DIW BERLIN

Discussion

Papers
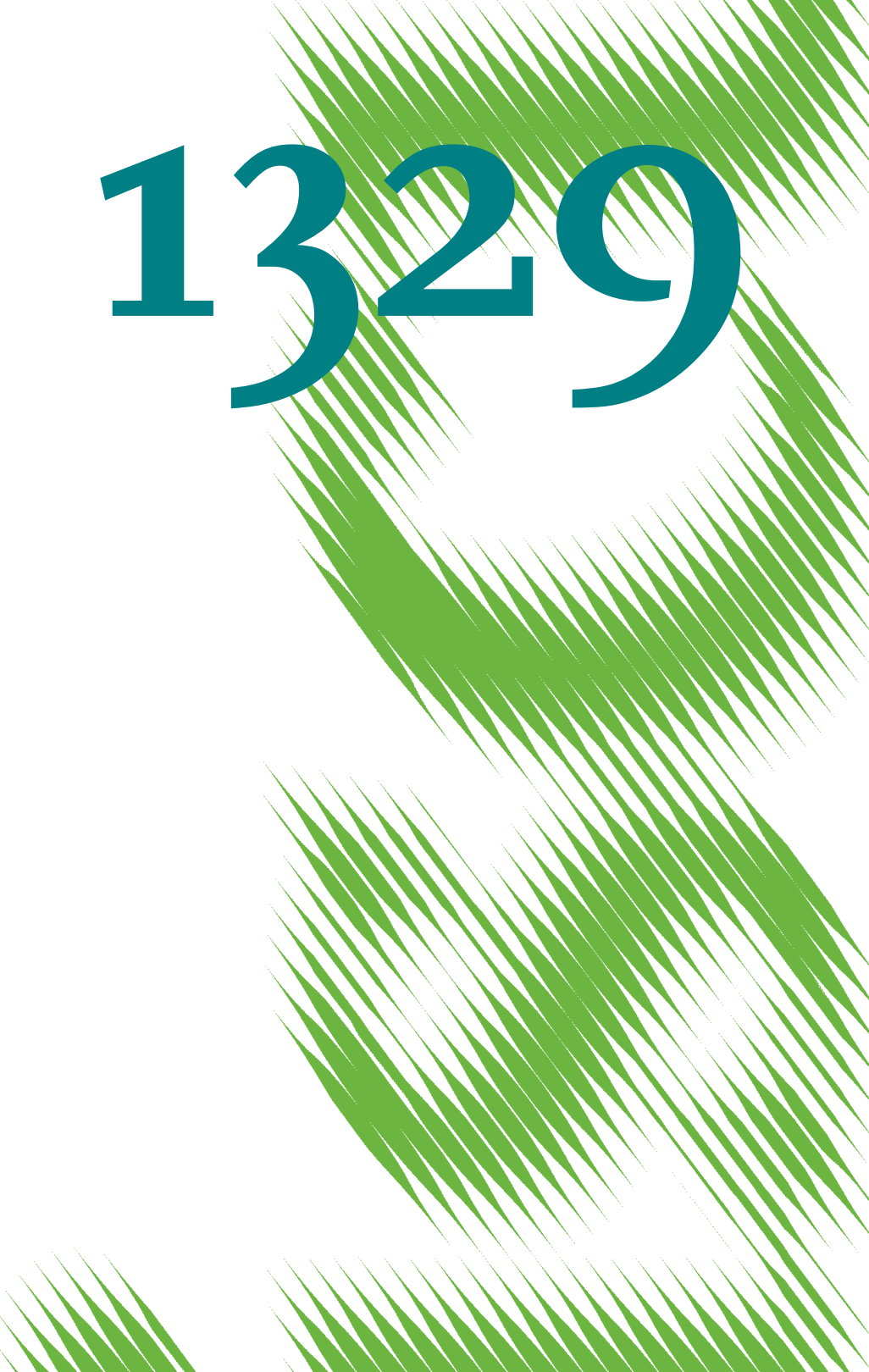

MMMMMMMMMMT

Long-Term Effects of Diabetes Prevention

Evaluation of the M.O.B.I.L.I.S. Program for Obese Persons 
Opinions expressed in this paper are those of the author(s) and do not necessarily reflect views of the institute.

IMPRESSUM

(C) DIW Berlin, 2013

DIW Berlin

German Institute for Economic Research

Mohrenstr. 58

10117 Berlin

Tel. $+49(30) 89789-0$

Fax +49 (30) $89789-200$

http://www.diw.de

ISSN print edition $1433-0210$

ISSN electronic edition 1619-4535

Papers can be downloaded free of charge from the DIW Berlin website:

http://www.diw.de/discussionpapers

Discussion Papers of DIW Berlin are indexed in RePEc and SSRN:

http://ideas.repec.org/s/diw/diwwpp.html

http://www.ssrn.com/link/DIW-Berlin-German-Inst-Econ-Res.html 


\title{
Long-term effects of Diabetes prevention: \\ Evaluation of the M.O.B.I.L.I.S. Program for Obese Persons
}

\author{
Jan Häußler* and Friedrich Breyer
}

September 23, 2013

\begin{abstract}
In response to the growing burden of obesity, public primary prevention programs against obesity have been widely recommended. Several studies estimated the cost effects of diabetes prevention trials for different countries and found that diabetes prevention can be costeffective. Nevertheless, it is still controversial if prevention conducted in more real-world settings and among people with increased risk but not yet exhibiting Increased Glucose Tolerance can really be a cost-effective strategy to cope with the obesity epidemic. We examine this question in a simulation model based on the results of the M.O.B.I.L.I.S program, a German lifestyle intervention to reduce obesity, which is directed on the high-risk group of people who are already obese. The contribution of this paper is the use of 4-year follow-up data on the intervention group and a comparison with a control group formed by SOEP respondents as inputs in a Markov model of the long-term benefits of this intervention due to prevention of type-2 diabetes.
\end{abstract}

JEL-classification: I12, H51

Keywords: diabetes prevention, cost-benefit analysis, Markov modeling

*Corresponding Author. Address: Department of Economics, University of Konstanz, Fach 135, 78457 Konstanz, Phone: +497531-882189, e-mail: Jan.Haeussler@uni-konstanz.de

Acknowledgement: This research was funded by the German Ministry of Education and Research (BMBF) under the grant no. 0315671 and by BARMER GEK. The authors are grateful to M.O.B.I.L.I.S. e.V. for collecting and providing the data. 


\section{Introduction}

One of the main challenges for population health in the developed world is the steady increase in obesity. In the US, in 2009-2010, 35.7 per cent of the adult population was obese (Ogden et al., 2012), and in several European countries such as Spain and Germany, the corresponding percentages lay between 14.7 and 23 per cent. (Brunello et al., 2009; Mensink et al., 2013). The reasons for this trend are a combination of increased intake of calories and reduced physical activity (Finkelstein et al., 2005) and the resulting energy imbalance not only leads to a continuous weight gain but also to severe chronic conditions such as type 2 diabetes. Globally, it is estimated that 438 million people (7.8\% of the adult population) will have developed type 2 diabetes by 2030 unless effective prevention programs are implemented (International Diabetes Federation, 2009). Diabetes and other diseases emerging as consequences of excessive weight will also cause a sizable economic burden (Guh et al., 2009) through direct medical costs of treatment as well as indirect costs of illness such as disability and early retirement (Konnopka et al., 2009; Finkelstein et al., 2003).

In response to this growing burden of obesity, public primary prevention programs against obesity have been widely recommended (WHO 2004). The European guideline for the prevention of type 2 diabetes focuses on obesity and sedentary lifestyle as these are the main modifiable risk factors of the disease (Paulweber et al., 2010). Several studies (Lindgren et al., 2007; DPP Research Group 2003; Icks et al., 2007; Bertram et al., 2010) estimated the cost effects of diabetes prevention trials for different countries. The studies differ with regard to intervention, population, time-perspective, measurement of the costs but they all find that diabetes prevention can be cost-effective (see reviews by Paulweber et al. 2010 and Klein et al., 2011). Furthermore, Li et al., 2010 found that among all different interventions recommended by the American Diabetes Association (ADA), evidence was strongest for the cost-effectiveness of intensive lifestyle modification among persons with impaired glucose 
tolerance (IGT). Nevertheless, it is still controversial if prevention conducted in more realworld settings and among people with increased risk but not yet exhibiting IGT can really be a cost-effective strategy to cope with the obesity epidemic. We examine this question in a simulation model based on the results of the M.O.B.I.L.I.S program, a German lifestyle intervention to reduce obesity, which is directed on the high-risk group of people who are already obese. The contribution of this paper is the use of a Markov model to measure longterm benefits of this intervention due to prevention of type-2 diabetes.

This paper is organized as follows. Section 2 is devoted to a description of data and methods and first presents an overview of the M.O.B.I.L.I.S. intervention and the analyzed data, followed by a characterization of the Markov model framework and the cost-benefit analysis. Section 3 presents the results of the medium-term simulation and some sensitivity analyses. In Section 4 we discuss our findings. Concluding remarks are offered in Section 5.

\section{Data and Methods}

Overview of the M.O.B.I.L.I.S. Intervention

The M.O.B.I.L.I.S. program is a lifestyle intervention to reduce obesity. The program has been implemented nationwide in Germany since 2005, with by now over 6000 participants. The program addresses obese adults (BMI $30-40 \mathrm{~kg} / \mathrm{m}^{2}$ ) who have at least one obesity-related risk factor but are still capable of light exercise. Individuals with type-1 diabetes or several other diseases are not allowed to participate. The intervention includes physical activity, nutritional and behavioral advice in more than 50 group sessions over a time period of 12 months. Details of program design are documented in Lagerstrøm et al. (2013).

What makes the M.O.B.I.L.I.S. intervention particularly interesting for a health economic evaluation is the fact that participation fees are to a large extent reimbursed by public health insurance. The participants have to pay participation fees of $785 €$ (before 2008: $685 €$ ) in 
advance but upon completion of the program all but a co-payment of $100 €$ is returned by the sickness fund. Thus, besides their intrinsic motivation to improve their health status, the participants have an additional monetary incentive to attend the program sessions till the end once they started the program.

The effectiveness of the intervention in reducing weight and enhancing physical activity of the participants over the intervention period has been documented in the studies by Lagerstörm et al. (2013) and Berg et al. (2008). Frey et al. (2010) also show that the intervention effects are persistent one year after program termination. Compared to the initial levels average weight was reduced by $6.8 \mathrm{~kg}( \pm 7.8)$ and weekly physical activity was significantly higher. Besides that, Göhner et al. (2012) find that compared to a quasiexperimental control group the participants show significantly enhanced psychological variables (self-efficacy, strength of goal intention) at a two-year follow-up.

\section{Year Follow-up}

The present follow-up study conducted in 2011 and 2012 allows the evaluation of long-term effects of the M.O.B.I.L.I.S. program. The follow-up periods after completion of the intervention vary between 3 and 6 years with an average follow-up period of about 4 years after the end of participation. To rule out seasonal effects the participants were contacted in the same calendar month in which they had completed the program. A total of $\mathrm{N}_{0}=958$ individuals that had completed the program, had taken part in the one-year follow-up and fulfilled the inclusion criteria (before the intervention: age 40-60 yrs., BMI 30-40 kg/m², no type-2 diabetes) were asked by mail and additional personal phone calls to participate in the study. A response rate of $42 \%$ results in a study sample of $\mathrm{N}=401$ individuals, with average age 49.8 yrs. $( \pm 5.7)$, average BMI $34.9 \mathrm{~kg} / \mathrm{m}^{2}( \pm 2.7)$ and a female share of $82.5 \%$. All medical and anthropometric values of the sample are reliable, as they were measured and 
documented by physicians. Additional lifestyle related items (physical activity, nutrition) were raised on a questionnaire basis.

\section{[Insert Table 1]}

The descriptive statistics in Table 1 provide an overview of the sample characteristics before and after the intervention, as well as for the 4-year follow-up. The obesity measures (BMI, Waist-to-Hip ratio (WHR)) and reported physical activity have a common pattern over time. Compared to the baseline, the intervention still has a positive effect at the follow-up, though there is a clear rebound effect when we regard the development after completion of the program. Looking at the other medical risk indicators, the interpretation is not as clear. For blood pressure, LDL cholesterol and fasting blood sugar the initial improvements after the intervention vanish, as the follow-up levels meet the baseline values. HDL cholesterol and HbAlc show a rising time trend, which might be due to general age effects (Davidson et al., 2010) overlapping possible intervention effects.

In order to check for possible self-selection effects in the follow-up sample we compare the responders to the non-responders with respect to their initial weight loss during the program. The differences are not very strong, though we cannot exclude a self-selection bias for participation at the study. Among responders, 61.4 per cent had experienced a weight loss of more than $5 \%$ during program participation, whereas the respective number among the nonresponders was only 49.9 per cent, see Figure 1 for details. The response rate of those with an initial weight loss of less than 5\% was 35.7 per cent, compared to 46.9 per cent for those who lost more than $5 \%$ during the program.

[Insert Figure 1] 


\section{Control Group}

For an informative evaluation of the economic benefits of the intervention, based on the development of the risk factors we need to account for the general age-related trend in the population, which is achieved by including a control group. Due to the real-world implementation of the M.O.B.I.L.I.S. program and the retrospective study design, we are lacking an original randomized control group. We overcome this problem with the aid of an artificial control group, formed from a subgroup of $\mathrm{N}_{0}=1308$ individuals of the German socioeconomic panel (SOEP) who meet the same inclusion criteria at the beginning of the intervention. The SOEP sample is representative for the German population so that comparability for socio-economic and other background variables should be reasonably high. We performed propensity score matching estimated on the baseline covariates BMI, age and gender for the 2-nearest neighbors in the SOEP sample to build our artificial control group. The SOEP dataset only contains information on weight and BMI as diabetes risk factors, so we lose the information on the additional risk indicators in the M.O.B.I.L.I.S. dataset in the control group. As data on weight is available in the SOEP sample only every two years, we compute the annual BMI development to account for the one-year period of the intervention.

The average development in the matched control group in comparison to the measured intervention group values can be found in the first column of Table 2. Being matched on the baseline BMI the control group shows no significant change in BMI in the period until completion of the program. Over the 4 years of the follow-up period the average BMI in the control group grows at a low rate from 34.458 to $35.088 \mathrm{~kg} / \mathrm{m}^{2}$, and compared to the baseline value of $34.887 \mathrm{~kg} / \mathrm{m}^{2}$ the overall rise in weight of the control group is not significantly different from zero. Thus the average BMI in the control group is more or less constant over the observed period, while the intervention group shows the pattern of initial weight loss and a rebound in the following 4 years as described before. 
[Insert Table 2]

The observed BMI reduction from the start to the end of the intervention is 7.37 per cent, while the estimated average treatment effect (ATE) of BMI development is a 5.87 per cent reduction for the intervention group, compared to the control group. In the period between completion and 4-year follow-up the observed BMI in the intervention group grows by 4.60 per cent, whereas the ATE in this period only shows a 2.75 per cent rise in BMI for the intervention group. As the ATE is significantly below the observed rebound effect in the intervention group, we can state that weight regain effects of the intervention group at the follow-up are on average lower when we take the representative control into account. The differences in distribution over the three obesity subgroups overweight, obese and severely obese $(\mathrm{BMI}<30,30 \leq \mathrm{BMI} \leq 35, \mathrm{BMI}>35)$ in the M.O.B.I.L.I.S. population and the control group are presented in Table 2. All statistical analyses were performed using Stata 12.

\section{Simulation framework}

Evaluating the long term effects of the M.O.B.I.L.I.S. intervention requires information on the development of obesity related diseases beyond the data of the 4 year follow-up. Abstracting from other diseases such as myocardial infarction and stroke, our analyses focus on the development of diabetes based on the individual obesity level. Using a Markov cohort simulation we estimate the long-term effects of the M.O.B.I.L.I.S. intervention on the prevalence of type- 2 diabetes in the control and the intervention group. The Markov model is a variation of the model used in a former study to evaluate the Finnish GOAL Intervention (Haeussler et al., 2012).

[Insert Figure 2]

The state-transition Markov model consists of five mutually exclusive (disease) states and discrete one-year intervals. The model structure depicted in Figure 2 allows us to follow the starting population over a 20 -year time horizon, by the annual forecasts for every state of 
interest. We limit the time horizon of the Markov model to 20 years because we think that any weight differences observed between the groups at a later time can no longer be traced back to the intervention. This is in line with findings of previous follow-up studies (DPP Research Group 2009). Members of the intervention and control groups move between the Markov states according to given transition probabilities (see Table 3 for an overview). Both groups enter the model at stage zero according to the observed (estimated) distributions over the model states at the 1-year follow-up. The five Markov states are: 1) no diagnosed diabetes and $B M I<30,2)$ no diagnosed diabetes and $30<B M I<35,3)$ no diagnosed diabetes and $B M I>$ 35 (afterwards we will refer to these states as "non-diabetes"), 4) diagnosed diabetes and 5) the absorbing Markov state death. The initial age of the individuals entering the Markov model is 54 years, which is consistent with the average age at the follow-up in both groups. With respect to the gender shares we simulate the model according to the mixed composition in the follow-up sample and in a separate subgroup analysis for females only. We do not run a separate subgroup for males, as the low number of male participants makes a sound analysis impossible.

\section{[Insert Table 3]}

The annual transition probabilities between the three non-diabetes states are computed from the analysis of the BMI development between the end of the M.O.B.I.L.I.S. intervention and the follow-up 4 years later, and the respective changes in the control group. We do not further consider the BMI progress within the year of the program for the computation of the transition probabilities, as this would implicitly assume regular repetition of the intervention. However, the singular one year intervention effect is captured by the composition of the intervention (control) group with respect to the Markov states at the start of the simulation. To account for a further equalization in weight development of the intervention group to the general time trend reflected by the control group, we assume a linear adjustment of the non- 
diabetes transition probabilities to the control group values over 10 years. This assumption is in line with previous findings on long term effects of weight reduction (DPP Research Group 2009, Norris et al. 2005), however we will relax it in the sensitivity analysis. We also assume that annual weight changes are not big enough to jump from the lowest to the highest nondiabetes state (or vice versa) in one step.

All other annual transition probabilities are based on the results of other studies and German epidemiological data: non-diabetes to diabetes (Rathmann et al., 2009; Bonora et al., 2004), non-diabetes to death and diabetes to death (Statistisches Bundesamt 2010; GBE 2006; Bender et al., 2006), are all one way. The transition probabilities to the state of death are adjusted to the gender composition of the samples and they are age-dependent in 5-year steps. Due to missing data the transition from non-diabetes to death does not differ by BMI category. All people who die remain in this state forever and we only regard diagnosed cases of type-2 diabetes mellitus where no cure is feasible. Those probabilities are assumed to be equal for the two groups of individuals but they vary by age and are adjusted to the gender composition of the groups.

All simulations were performed using TreeAge Pro Healthcare (Release 1.0 b1, 2001; TreeAge Software Inc.).

\section{Cost-benefit analysis}

The results of the Markov simulation are the foundation of the subsequent cost-benefit analysis. The analysis adopts the perspective of the health insurance system and abstracts from effects on human capital, work loss etc. Also, subjective utility from the health state does not enter the cost-benefit analysis. We measure the direct costs of diabetes by monetizing the simulation outcomes for diabetes prevalence in each year and in both groups. The diabetes costs in year $i$ are defined by the following equation:

Costs $\_$igroup $=\left[\right.$Costs_w/o complications + Rate i_complications $^{*}$ Costs_with comp $]{ }^{*}$ Prevalence $\_$igroup. 
Discounted overall costs of diabetes for each group are respectively:

$\operatorname{COSTS}_{\text {group }}=\sum_{i=0}^{20} \frac{1}{(1+r)^{i}} \operatorname{Cost}_{\left\{i_{-} \text {group }\right\}}$

Based on the results by Guh et al., 2009, we assume no complications for the first 5 years and afterwards a linear increase to an average complication rate of $25 \%$ from 10 years on. Regarding the treatment costs of diabetes in Germany we use the value of $850 €$ for the disease without complications and 8,830 € with complications (Köster et al. 2006 and 2011).. The intervention costs - for a health insurer - are $685 €(585 €$ before 2009$)$, resulting in average intervention costs according to the sample composition of $673 €$. For our evaluation we only take into account the costs without the deductible of $100 €$, as we adopt the perspective of the sickness fund. All costs are expressed in 2011 Euros and all future costs were compounded at an annual discount rate $r$ of 3 per cent.

\section{Sensitivity analyses}

To check for the validity of our results we conducted one-way sensitivity analyses regarding the values of all parameters of the model.

\section{Results}

\section{Mortality}

The simulated cumulative annual mortalities depicted in Figure 3, for the mixed gender groups, indicate that the intervention has no significant effect on the longevity of the individuals. The overall time trend of the mortality rates is the same for intervention group and control group, with the annual rates differing only at insignificantly low margins. The cumulative mortality after 20 years is $27.00 \%$ in the control group compared to $27.28 \%$ in the intervention group. The difference in average annual mortality rates between $1.35 \%$ in the 
control group and $1.36 \%$ in the intervention group is not significantly different from zero, either. The simulation results for the female subgroup show that the described mortality effects are independent of the gender composition of the groups. In this case the cumulative mortality rate after 20 years is $20.26 \%$ (20.05\%) in the intervention (control) group. Summarizing the results we can state that, at least in our model setup, the M.O.B.I.L.I.S. intervention has no effects on long-term mortality rates.

\section{[Insert Figure 3]}

\section{Diabetes prevalence}

The annual prevalence rates of diabetes over the 20 years of the simulated time horizon are depicted for the intervention group and the control group in Figure 4. The prevalence level in the intervention group is markedly below that in the control group over all the 20 years, with an average annual rate of $4.59 \%$ in the intervention group compared to $6.87 \%$ in the control group. The simulated diabetes prevalence at the end of the simulation is $31.9 \%$ lower in the intervention group than in the control group, with an absolute difference of 4.73 percentage points. The estimated diabetes prevalence in the M.O.B.I.L.I.S. population would be considerably lower if the success of the intervention persisted over the whole period. Looking at the literature on the long-term effects of other interventions (Norris et al. 2005, Tuomilehto et al. 2001) this scenario seems unrealistic but we included the simulation as a benchmark in the sensitivity analysis.

\section{[Insert Figure 4]}

The diabetes prevalence for the female subgroup shows the same pattern as described above for the mixed group, though the differences in prevalence rates are a bit less pronounced. On average the annual prevalence rate is $3.67 \%(5.10 \%)$ in the intervention (control) group. At the end of the simulated time horizon the diabetes prevalence is $8.04 \%$ in the intervention 
group compared to $10.97 \%$ in the control group. This prevalence being $26.7 \%$ lower in the intervention group compared to $31.9 \%$ in total indicates that the male share of the mixed sample has a positive influence on the effectiveness of the intervention as a whole.

Based on the diabetes prevalence projections we can make a first statement on the effectiveness of the M.O.B.I.L.I.S. intervention. The incremental cost-effectiveness ratio (ICER) of the intervention, for the mixed group setup, results as $343.10 €$ per percentage point of average diabetes prevalence over the period of 20 years.

\section{Cost-benefit Analysis}

As discussed in the methods part, the results of the cost-benefit analysis depend on the average time between the onset of type 2 diabetes and the onset of complications (see Table 4 for an overview). In the extreme case of no complications at all, the M.O.B.I.L.I.S. intervention does not pay off from the perspective of a sickness fund. In that situation with annual type- 2 diabetes costs of $850 €$ the difference in the discounted diabetes costs between control and intervention group amounts to $446 €$. With average intervention costs of $673 €$ for a sickness fund this leads to a negative net-benefit of $227 €$ for the mixed group and $269 €$ for the female subgroup.

\section{[Insert Table 4]}

Following the rationale of the computation described in the methods part - with an average time till the onset of complications of 10 years - the M.O.B.I.L.I.S. intervention has a positive net-benefit. Based on the assumption that the costs of type- 2 diabetes rise linearly from $850 €$ (cost without complications) in the first 5 years after diagnosis to $3057 €(25 \%$ complications on average) in year 10 and afterwards, the differences in diabetes cost are as follows. The discounted diabetes costs cumulated over the whole period of 20 years are $1000 €$ lower for individuals form the intervention group than for those from the control group. For the mixed 
gender group this results in a positive net-benefit of $327 €$ from the perspective of a sickness fund. The positive result also holds for the female subgroup, with a net-benefit of $299 €$.

\section{Sensitivity Analyses}

The analysis in the previous section shows that the results of the CBA are affected by the assumed timespan before diabetes with complications sets in. But only in the extreme case without any complications the results are affected qualitatively. Altering the timespan from 10 years to 5 or 15 years shows that the results are robust for moderate changes on this model parameter and provides a confidence interval for the magnitude of net-benefits. For 5 years until the onset of complications the positive net-benefit is $411 €$, while for 15 years the Figure is reduced to $269 €$, both for the mixed group.

\section{[Insert Figure 5]}

As discussed above, the results of the CBA are sensitive to the assumed parameters. After checking for the effect of the variation of each parameter the results of the model turn out to be robust for all sensible parameter values. A summary of the single variations is presented in the tornado diagram of Figure 5, where the width of a single bar reflects sensitivity of the diabetes costs for a variation in the respective parameter. The dotted vertical line in the diagram stands for the breakeven point in the CBA for the mixed group as discussed above. When a single parameter variation affects the breakeven of the CBA in general this is depicted by a bold vertical line in the respective bar. Thus for example the variation of the start age of the individuals entering the model does not affect the CBA, in the sense that the intervention has a positive net-benefit for the whole interval from 45 to 65 years. For all other parameters the choice of the assumed value might affect the evaluation of the intervention. But looking at the parameters in detail the assumed values in the model specification are for each of them far away from the critical values. Thus we can summarize that the specification of the model parameters does not drive the positive results of the CBA. 
Assuming an adjustment of the BMI development in the intervention group to the trend in the control group should be considered critical, as it influences our results considerably. Without this adjustment, the CBA results change significantly. The resulting net-benefit of the intervention drops to $129.7 €$, compared to $327 €$ under the above assumption for the mixed group. The similar effect can be observed in the female subgroup were the net benefit drops from $299 €$ to $124.8 €$ without the adjustment assumption.

\section{Discussion}

We are well aware of the limitations and shortcomings of the current study that have to be considered. The first point to look at is the lack of a randomized control group for the evaluation. Although we are missing socioeconomic background variables for the intervention group to compare them directly with our matched control group, differences with respect to socioeconomic status should be a minor problem as the intervention group was recruited all over Germany and the control group is a matched representative subsample of the German population. The main problem of the artificial control group is, of course, that we cannot account for a possible selection bias with respect to participation in the intervention for the control group. This might exaggerate the effects for the intervention group - as participants have the intention to lose weight - but this will not alter the implications of the analysis for the evaluation of public prevention programs. As long as prevention programs offered by sickness funds are voluntary we will always observe comparable self-selection of participants.

Besides this selection effect at the baseline, we have to consider the differences between responders and non-responders at the 4 year follow-up, as mentioned in the data section and depicted in Figure 1. The follow-up responders had on average a larger weight loss by the end of the program, what might in general exaggerate the long term effectiveness of the whole intervention in the present analysis. However, looking at BMI development between the 
completion of the program and the follow-up in detail, it appears that this self-selection of responders does not obviously bias our findings in one direction. The effect of an initial BMI decline on the BMI development in the 4 year follow-up period is significantly negative, with an estimated coefficient of -0.429 (SE: 0.054). Thus the observed rebound effect is stronger for those who lost more weight during the program. This larger regain in BMI has in turn negative consequences for the long-term effectiveness of the intervention. Considering these two points it is not clear that the larger share of initially successful responders in the followup overstates the benefits of the intervention.

Regarding the structure of the Markov model two points can be criticized, the pure foundation on BMI changes and the focus on diabetes as the only cost relevant outcome. We think the former issue is justified by the fact that our control group dataset does not allow for a richer model, as the BMI is the only relevant risk factor we can observe. The focus on the cost of diabetes might understate the effectiveness of the intervention in the CBA as we omit possible benefits due to other obesity associated diseases. Consequently we regard our positive netbenefit results as a lower benchmark for the effectiveness of the M.O.B.I.L.I.S. intervention and think that considering further diseases should add further benefits. The effect on the simulated mortality should on the other hand be minimal, as the overall mortality rates for obese persons used in the model as transition probabilities reflect the other diseases as well.

Conducting the CBA from the perspective of the health care system might neglect some additional benefits for the society at large. Nevertheless we think the health care system perspective is the right one for this analysis as we evaluate a program advertised and reimbursed by sickness funds. Besides looking at the simulation results we think there is another point for our perspective. As projected mortality rates in the intervention group and control group do not differ significantly, taking those effects into account would not change the CBA results we found form the perspective of the health care system. A further issue is 
that our analysis neglects sick leave costs of diabetes. This is a valid point, although in our model framework these costs - for a population with a starting age of 54 and a time horizon of 20 years - could only occur in the first years.

The difference in the magnitude of effects in the CBA between the mixed group and the female subgroup basically reflects the lower diabetes prevalence over the whole simulation horizon of women. On the other hand this effect is decreased by the higher female life expectancy. In combination with effects due to the composition of the mixed group we cannot make any predictions on the effectiveness for a subgroup of male participants.

\section{Conclusion}

In this paper we have shown that from the perspective of the health care system, real-world diabetes prevention programs for obese people such as the M.O.B.I.L.I.S. intervention may pay for themselves in the long run. We consider the net-benefit values of our study as a lower bound for the effectiveness of the intervention as we only evaluate the costs of diabetes. Taking avoided costs of further obesity related diseases into account would presumably raise the benefits of the intervention. On the other hand, the estimated benefits themselves may be slightly biased upward due to the (mild) self-selection of participants. It seems, however, reasonable to assume that this upward bias is smaller than the downward bias mentioned before. From a policy point of view the results indicate that allowing sickness funds to invest in prevention might help to reduce health care expenditures, if the funds are able to detect effective programs and address the appropriate target groups. 


\section{References}

Bender R., Zeeb H., Schwartz M., Joeckel K.-H., Berger M. (2006): Causes of death in obesity: Relevant increase in cardiovascular but not in all-cancer mortality. Journal of Clinical Epidemiology 59: 1064-1071.

Berg A., Berg A. jr., Frey I., König D., Predel H.G. (2008): Ergebnisse zu M.O.B.I.L.I.S. - einem Bewegungsorientierten Schulungsprogramm für adipöse Erwachsene. Deutsches Ärzteblatt 105 (11): 197-203.

Bertram M.Y., Lim S.S., Barendregt J.J., Vos T. (2010): Assessing the cost-effectiveness of drug and lifestyle intervention following opportunistic screening for pre-diabetes in primary care. Diabetologia 53(5): 875-81.

Bonora E., Kiechl S., Willeit J., Oberhollenzer F., Egger G., Meigs J.B., Bonadonna R.C., Muggeo M. (2004): Population-Based Incidence Rates and Risk Factors for Type 2 Diabetes in White Individuals - The Bruneck Study. Diabetes 53: 1782-1789.

Brunello G., Michaud P.-C., Sanz-de-Galdeano A. (2009): The rise of obesity in Europe: an economic perspective. Economic Policy 24: 551-596.

Davidson M.B., Schriger D.L. (2010): Effect of age and race/ethnicity on HbA1c levels in people without known diabetes mellitus: Implications for the diagnosis of diabetes. Diabetes Research and Clinical Practice 87: 415-421.

Diabetes Prevention Program (DPP) Research Group (2003): Within-Trial Cost-Effectiveness of lifestyle intervention or Metformin for the primary prevention of type 2 Diabetes. Diabetes Care 26: 2518-2523.

Diabetes Prevention Program (DPP) Research Group (2009): 10-year follow-up of diabetes incidence and weight loss in the DPPOS. The Lancet 374: 1677-86.

Finkelstein E.A., Ruhm C.J., Kosa K.M. (2005): Economic causes and consequences of obesity. Annual Review of Public Health 26: 239-257.

Finkelstein E.A., Fiebelkorn I.C., Wang G. (2003): National medical spending attributable to overweight and obesity: how much and who's paying? Health Affairs (Web Exclusive): W3-219-226.

Frey I., Dapp N., König D., Deibert P., Predel H.G., Berg A. (2010): Weight Management trough M.O.B.I.L.I.S., an Exercise Based Weight Loss Program: 2-Year Results. Deutsche Zeitschrift für Sportmedizin 61: 19-22.

Frey I., Berg A., Grathwohl D., Keul J. (1999): Freiburger Fragebogen zur körperlichen Aktivität - Entwicklung, Prüfung und Anwendung. Sozial- und Präventivmedizin 44: 55-64.

Göhner W, Schlatterer M, Seelig H, Frey I, Berg A jr, Fuchs R. (2012): Two-Year Follow-Up of an Interdisciplinary Cognitive-Behavioral Intervention Program for Obese Adults. The Journal of Psychology 146: 371-391.

Guh D.P., Zhang W., Bansback N., Amarsi Z., Birmingham C.L., Anis A.H. (2009): The incidence of co-morbidities related to obesity and overweight: A systematic review and meta-analysis. BMC Public Health 9: 88.

Häußler J., Hankonen N., Absetz P. (2013): Economic evaluation of the GOAL Lifestyle Intervention to prevent type 2 diabetes. Working Paper

Icks A., Rathmann W., Haastert B., Gandjour A., Holle R., John J., Giani G.; KORA Study Group (2007): Clinical and cost-effectiveness of primary prevention of Type 2 diabetes in a 'real world' routine healthcare setting: model based on the KORA Survey 2000. Diabetic Medicine 24: 473-80. 
International Diabetes Federation: IDF Diabetes Atlas. Retrieved September 19, 2009, http://www.diabetesatlas.org/ (2009). Accessed 18 September 2013

Klein A., Chernyak N., Brinks R., Genz J., Icks, A. (2012): Kosteneffektivität der Primärprävention des Typ-2-Diabetes. Prävention und Gesundheitsförderung 6: 102-110.

Konnopka A., Bödemann M., König H.-H.: Health burden and costs of obesity and overweight in Germany (2011). European Journal of Health Economics 12: 345-352.

Köster I., Huppertz E., Hauner H., Schubert I. (2011): Direct costs of diabetes mellitus in Germany - CoDiM 2000-2007. Experimental and Clinical Endocrinology \& Diabetes 119: 377-385.

Köster I., von Ferber L., Ihle P., Schubert I., Hauner H. (2006): The cost burden of diabetes mellitus: the evidence from Germany - the CoDiM Study. Diabetologia 49: 1498-1504.

Lagerstrøm D, Berg A jr, Haas U, Hamm M, Göhner W, Fuchs R, Predel HG, Berg A. (2013): Das M.O.B.I.L.I.S.-Schulungsprogramm. Bewegungstherapie und Lebensstilintervention bei Adipositas und Diabetes. Diabetes aktuell 11 (1): 5-11.

Li R., Zhang P., Barker L.E., Chowdhury F.M and Zhang X. (2010): Cost-effectiveness of interventions to prevent and control diabetes mellitus: a systematic review. Diabetes Care 33: 1872-1894.

Lindgren P., Lindström J., Tuomilehto J., Uusitupa M., Peltonen M., Jönsson B., de Faire U., Hellenius M.L.; DPS Study Group (2007): Lifestyle intervention to prevent diabetes in men and women with impaired glucose tolerance is cost-effective. International Journal of Technology Assessment in Health Care 23:177-83.

Mensink G.B.M., Schienkiewitz A., Haftenberger M., Lampert T., Ziese T., Scheidt-Nave C. (2013): Übergewicht und Adipositas in Deutschland. Bundesgesundheitsblatt 56: 786794.

Norris S.L., Zhang X., Avenell A., Gregg E., Schmid C.H., Lau J. (2005): Long-term nonpharmacological weight loss interventions for adults with prediabetes. Cochrane Database of Systematic Reviews 18: CD005270.

Ogden C.L., Carroll M.D., Kit B.K., Flegal K.M. (2012): Prevalence of obesity in the United States, 2009-2010. NCHS data brief, no 82. Hyattsville, MD: National Center for Health Statistics.

Paulweber B., Valensi P., Lindström J., Lalic N.M., Greaves C.J., McKee M., et al. (2012): A European Evidence-Based Guideline for the Prevention of Type 2 Diabetes. Hormone and Metabolic Research 42 (S 01): 3-36.

Rathmann W., Strassburger K., Heier M., Holle R., Thorand B., Giani G., Meisinger C. (2009): Incidence of Type 2 diabetes in the elderly German population and the effect of clinical and lifestyle risk factors: KORA S4/F4 cohort study. Diabetic Medicine 26: 1212-1219.

Tuomilehto J., Lindstrom J., Eriksson J.G., Valle T.T., Hamalainen H., Ilanne-Parikka P., Keinanen-Kiukaanniemi S., Laakso M., Louheranta A., Rastas M., Salminen V., Uusitupa M. (2001): Prevention of type 2 diabetes mellitus by changes in lifestyle among subjects with impaired glucose tolerance. The New England Journal of Medicine 344, 1343-1350.

WHO (2004): The Global Strategy on Diet, Physical Activity and Health, http://www.who.int/dietphysicalactivity/strategy/eb11344/en/index.html. Accessed 18 September 2013 


\section{Appendix}

Table 1: Descriptive Statistics of the M.O.B.I.L.I.S. Sample Development

\begin{tabular}{|c|c|c|c|}
\hline Variable & Baseline & Completion & Follow-up \\
\hline Weight $(\mathrm{kg})$ & $\begin{array}{l}98.603 \\
(12.246)\end{array}$ & $\begin{array}{l}91.305 \\
(13.046)\end{array}$ & $\begin{array}{l}95.683 \\
(14.299)\end{array}$ \\
\hline $\mathrm{BMI}\left(\mathrm{kg} / \mathrm{m}^{2}\right)$ & $\begin{array}{l}34.887 \\
(2.692)\end{array}$ & $\begin{array}{l}32.317 \\
(3.509)\end{array}$ & $\begin{array}{l}33.850 \\
(3.862)\end{array}$ \\
\hline WHR & $\begin{array}{l}0.926 \\
(0.078)\end{array}$ & $\begin{array}{l}0.909 \\
(0.078)\end{array}$ & $\begin{array}{l}0.917 \\
(0.082)\end{array}$ \\
\hline Heart rate (bpm) & $\begin{array}{l}78.005 \\
(12.269)\end{array}$ & $\begin{array}{l}73.990 \\
(11.036)\end{array}$ & $\begin{array}{l}70.972 \\
(9.478)\end{array}$ \\
\hline Blood pressure $_{(\mathrm{mmHg})}^{1}$ & $\begin{array}{l}132.5 / 85.8 \\
(15.9 / 9.1)\end{array}$ & $\begin{array}{l}126.1 / 82.3 \\
(15.3 / 10.6)\end{array}$ & $\begin{array}{l}132.1 / 82.5 \\
(15.0 / 9.4)\end{array}$ \\
\hline $\mathrm{HDL}_{(m g / d l)}$ & $\begin{array}{l}57.197 \\
(13.666)\end{array}$ & $\begin{array}{l}59.784 \\
(14.322)\end{array}$ & $\begin{array}{l}61.714 \\
(15.742)\end{array}$ \\
\hline $\operatorname{LDL}_{(m g / d l)}$ & $\begin{array}{l}133.418 \\
(33.015)\end{array}$ & $\begin{array}{l}131.811 \\
(32.639)\end{array}$ & $\begin{array}{l}133.952 \\
(33.798)\end{array}$ \\
\hline Fasting blood sugar ${ }_{(m g / d l)}$ & $\begin{array}{l}92.970 \\
(13.152)\end{array}$ & $\begin{array}{l}91.636 \\
(12.737)\end{array}$ & $\begin{array}{l}93.870 \\
(16.490)\end{array}$ \\
\hline HbAlc (in \%) & $\begin{array}{l}5.625 \\
(0.341)\end{array}$ & $\begin{array}{l}5.637 \\
(0.281)\end{array}$ & $\begin{array}{l}5.649 \\
(0.435)\end{array}$ \\
\hline Physical Activity $^{2}$ & $\begin{array}{l}22.879 \\
(21.416)\end{array}$ & $\begin{array}{l}37.031 \\
(27.352)\end{array}$ & $\begin{array}{l}34.305 \\
(27.269)\end{array}$ \\
\hline
\end{tabular}

$\mathrm{N}=401$, Standard errors in parenthesis.

${ }^{1}$ Systolic / Diastolic. ${ }^{2}$ Measured as MET per week. Based on the evaluation of the physical activity questionnaire developed by Frey et al. (1999).

Table 2: BMI Means and Subgroup Development

\begin{tabular}{l|c|ccc}
\hline & BMI $^{1}$ & $B M I<30$ & $30 \leq B M I<35$ & $35 \leq B M I$ \\
\hline Baseline Intervention $^{2}$ & 34.887 & 0.0 & 0.5287 & 0.4713 \\
& $(2.692)$ & & & \\
& & & & \\
Completion Intervention & 32.317 & 0.2718 & 0.5037 & 0.2244 \\
Completion Control & $(3.509)$ & & & \\
& 34.458 & 0.0698 & 0.4589 & 0.4713 \\
Follow-up Intervention & $(2.792)$ & & & \\
Follow-up Control & 33.850 & 0.1621 & 0.4514 & 0.3865 \\
& $(3.862)$ & & & \\
& 35.088 & 0.0474 & 0.4638 & 0.4888 \\
\hline
\end{tabular}

$\mathrm{N}=401$.

${ }^{1}$ measured in $\left(\mathrm{kg} / \mathrm{m}^{2}\right)$.

${ }^{2}$ Control matched on BMI at the baseline before the intervention. 
Table 3: Annual Transition Probabilities in the Markov Model

\begin{tabular}{l|ccccc}
\hline $\begin{array}{l}\text { transition to } \\
\text { from }\end{array}$ & BMI $<30$ & $30 \leq \mathrm{BMI}<35$ & $35 \leq$ BMI & Diabetes $^{2}$ & Death $^{2}$ \\
\hline \multirow{2}{*}{ BMI $<30$} & $\begin{array}{ccc}0.80298^{1} \\
0.63606\end{array}$ & $0.18302^{1}$ & 0 & 0.00834 & 0.00566 \\
& & & & & \\
$30 \leq \mathrm{BMI}<35$ & $0.02467^{1}$ & $0.83391^{1}$ & $0.11256^{1}$ & 0.02320 & 0.00566 \\
& 0.01526 & 0.89981 & 0.05607 & & \\
$35 \leq \mathrm{BMI}$ & 0 & $0.04142^{1}$ & $0.90911^{1}$ & 0.04381 & 0.00566 \\
& & 0.03502 & 0.91551 & & \\
Diabetes $^{2}$ & 0 & 0 & 0 & 0.99425 & 0.00575 \\
\hline
\end{tabular}

Upper line: intervention group, lower line: control group

${ }^{1}$ Depending on the assumed further weight development in the intervention group the values adjust to the control group over time.

${ }^{2}$ Values for the age 55-60. Age-dependent in 5-year steps.

Table 4: Overview of Net-Benefits

\begin{tabular}{|c|c|c|}
\hline Avg. Complications & Mixed Group & All Female \\
\hline no & $-227 €$ & $-269 €$ \\
\hline after 5 years & $411 €$ & $349 €$ \\
\hline after 10 years & $\mathbf{3 2 7} €$ & $\mathbf{2 9 9} €$ \\
\hline after 15 years & $269 €$ & $228 €$ \\
\hline
\end{tabular}

with the reference scenario printed in bold.

Figure 1: Influence of Initial Program Success

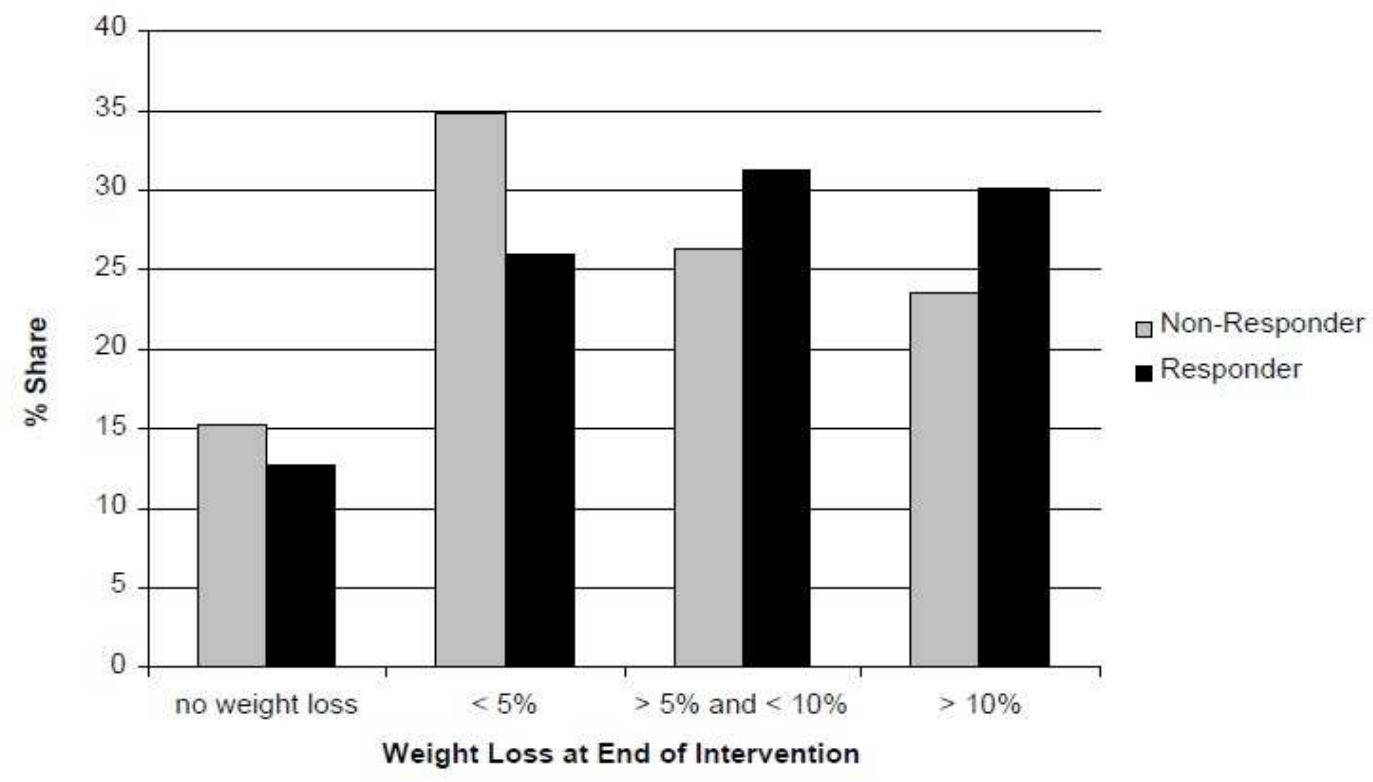


Figure 2: States of the Markov Model

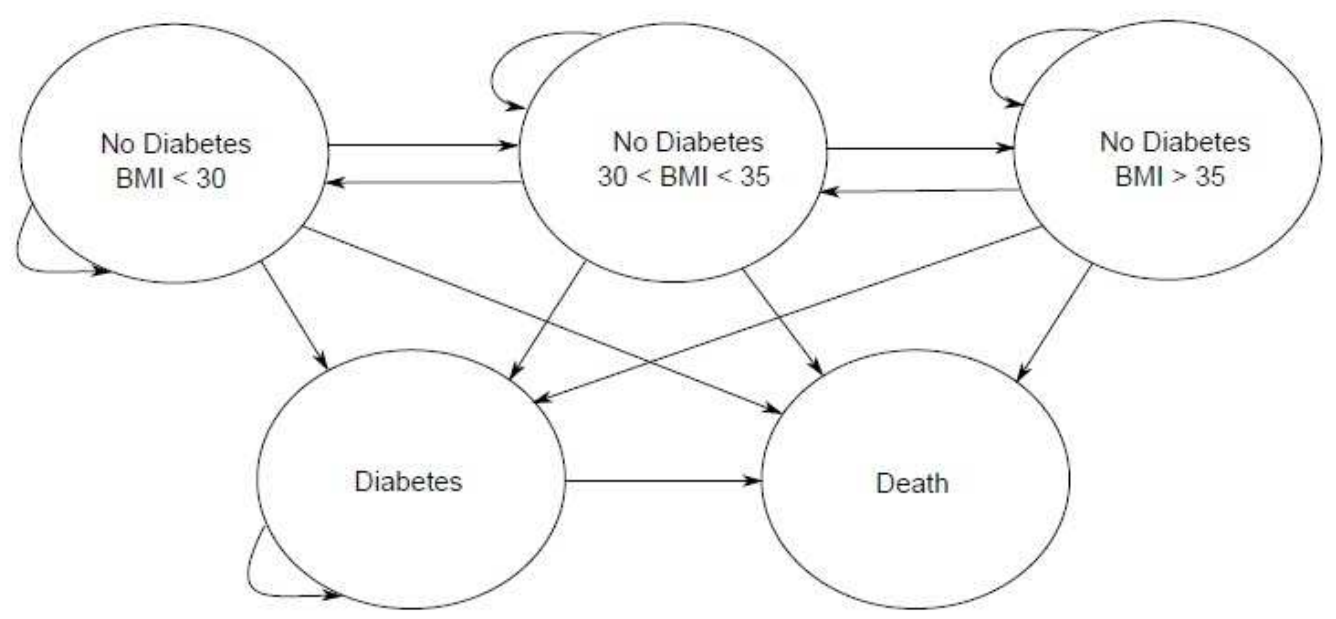

Figure 3: Cumulative Mortality Rate

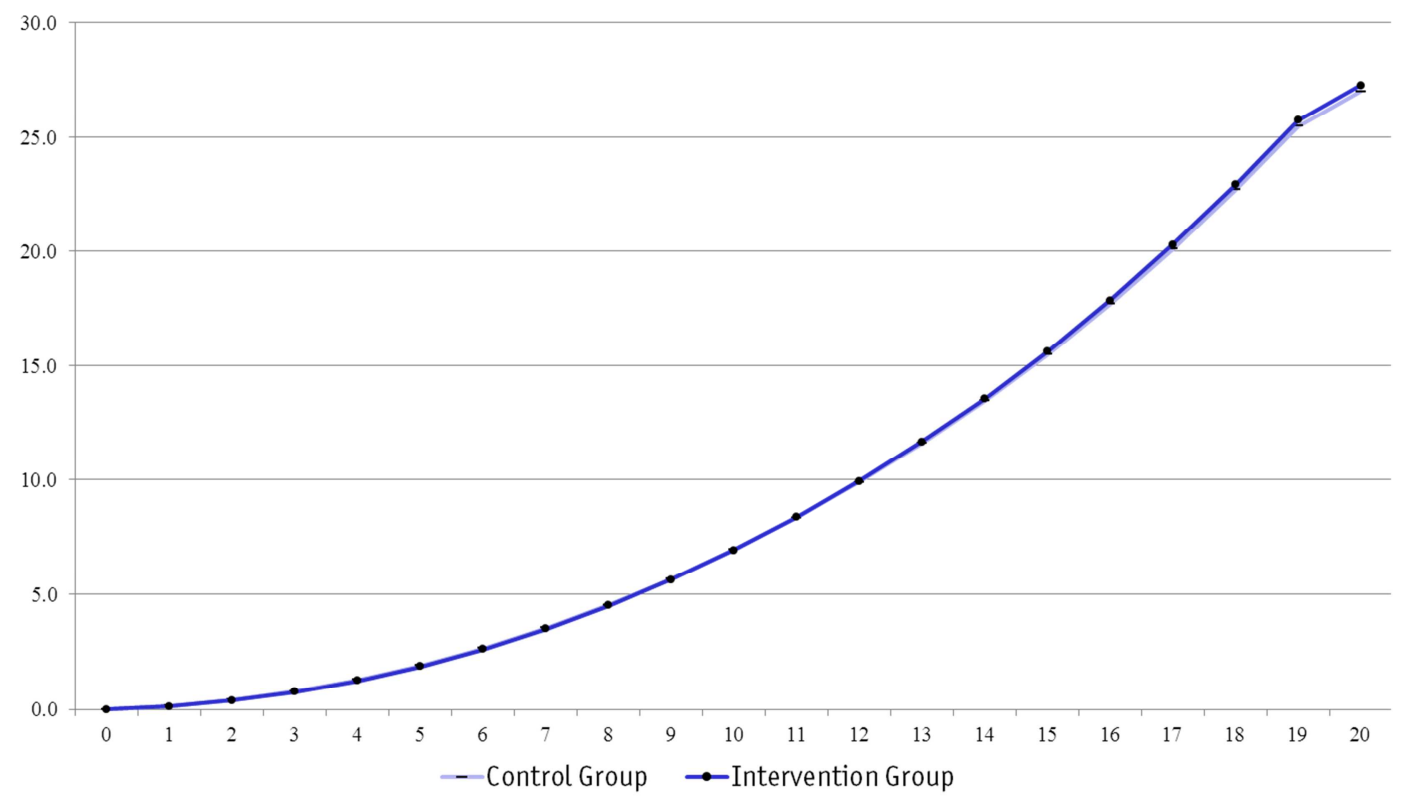


Figure 4: Annual Diabetes Prevalence Rate

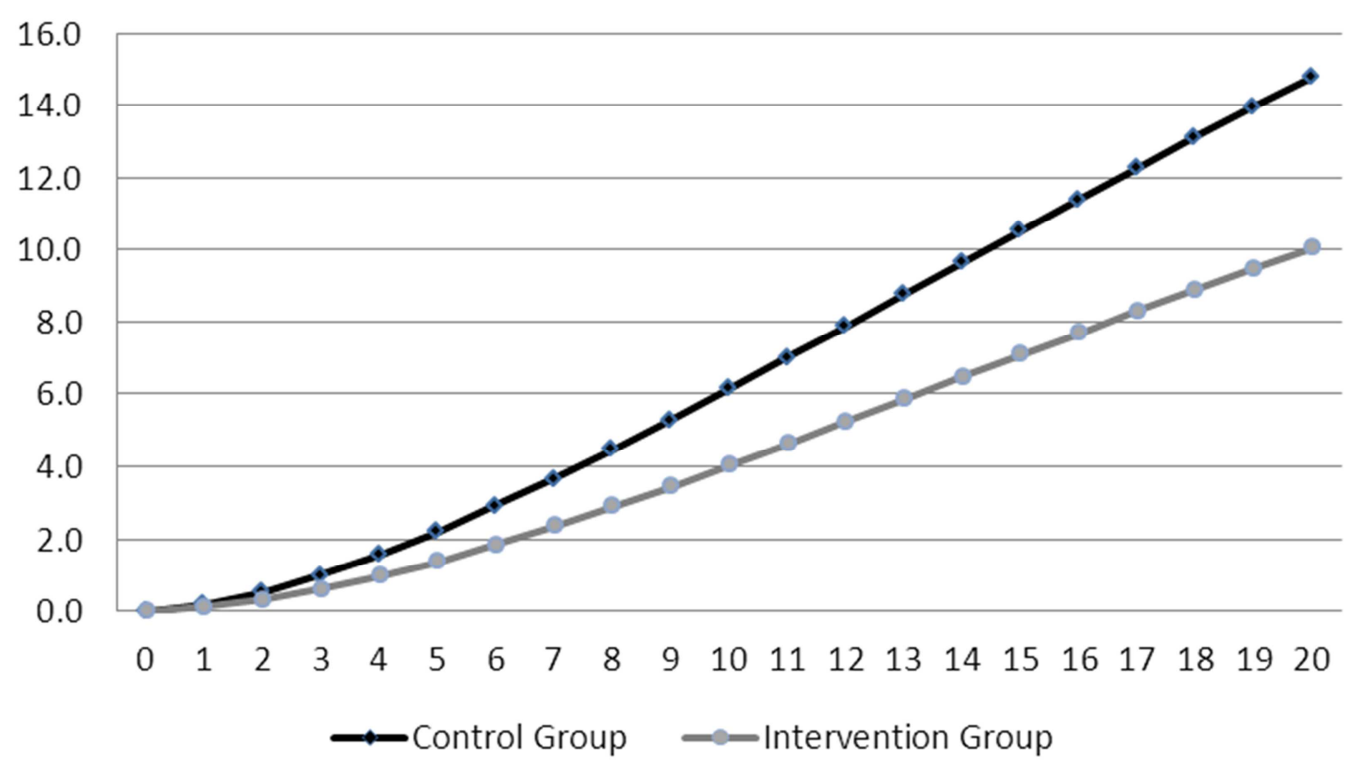

Figure 5: Tornado Diagram of the Model Parameters

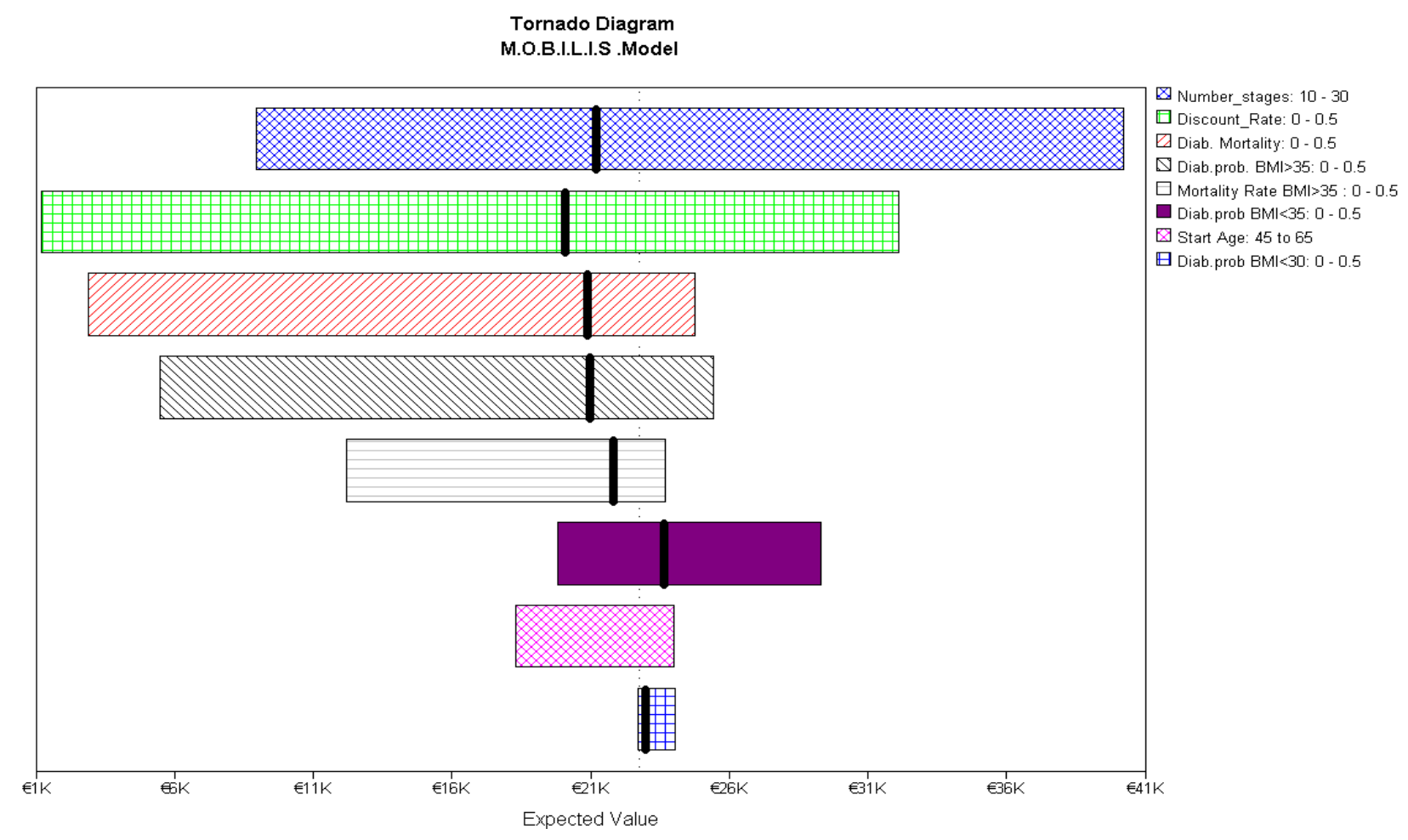

